\title{
09 | Wakonyousai. \\ Con corazón japonés, al estilo occidental. Objetualidad en el espacio doméstico japonés en el periodo 1850-1880: aprendiendo a convivir con la silla_Nadia Vasileva
}

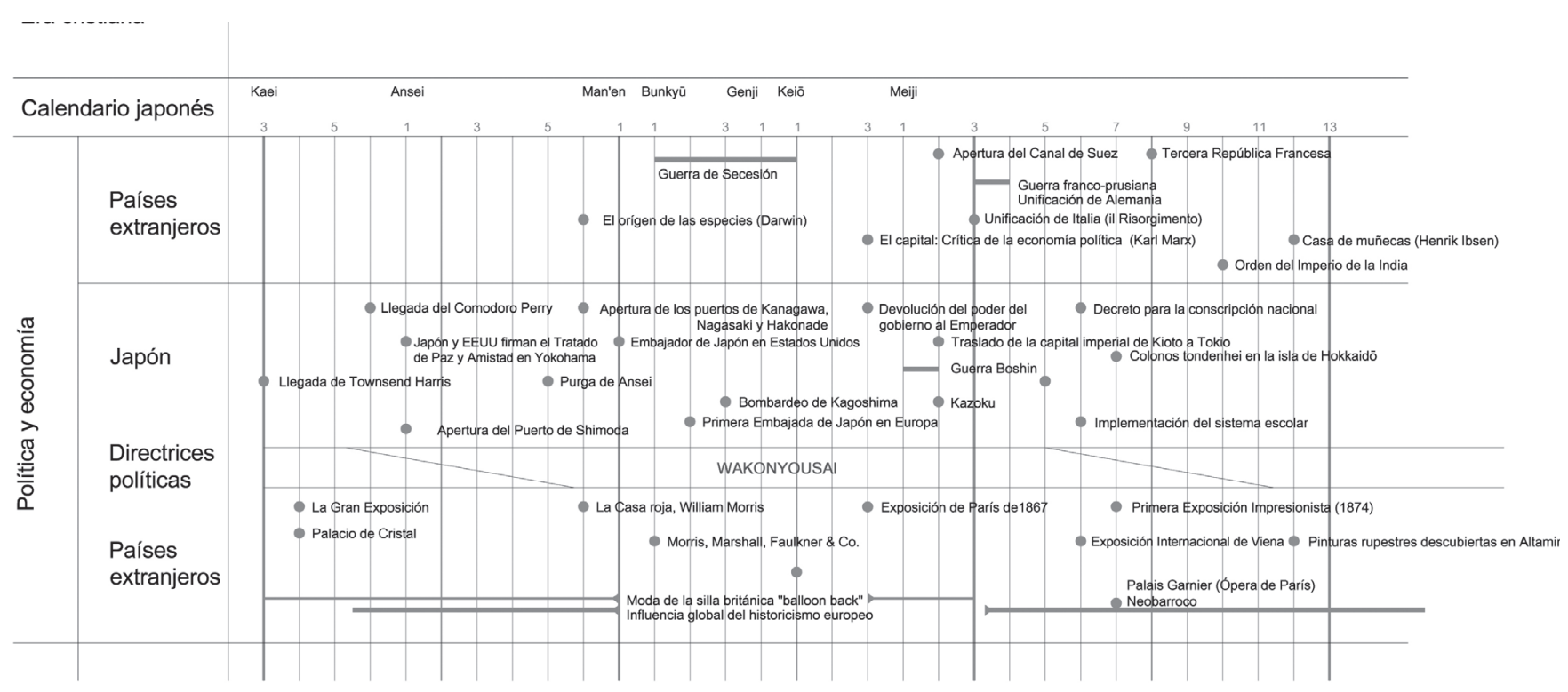

[2]

Tanto Occidente como Japón han experimentado de manera similar, aunque con diferencia en el tiempo, el problema de la pérdida de identidad de la vivienda a lo largo de la segunda mitad del siglo pasado. Mientras que en Occidente este fenómeno ha sido mucho más acusado, Japón, un país geográficamente condicionado por encontrarse aislado, ha preservado con mayor éxito algunas de las características esenciales del espacio doméstico, en particular en relación a las costumbres y hábitos. Si aceptamos el artefacto doméstico como punto focal de la existencia y como unidad básica de la configuración espacial (HERREROS, 1994), podemos analizar los principios que rigen una forma de vida particular -los patrones culturales, las costumbres y tradiciones- con el fin de transpolar su significado al objeto físico concreto.

\section{El diseño japonés: tradición-recreación}

El diseño japonés contemporáneo, en el campo del hábitat doméstico, constituye un ejemplo notable de reinvención del objeto desde el retorno a la tradición y representa un estudio de caso importante para todo Occidente. El énfasis se desplaza desde el espacio habitado, como contenedor, hacia los objetos domésticos y los hábitos de la vida cotidiana -desde la alimentación y la higiene a los hábitos de vestir-. De este modo, la reflexión se centra en el protagonismo del objeto en la generación del espacio habitado, haciendo alusión a "cómo un instrumento aparentemente insignificante" podría ser precursor y, a la vez, resultado de la idiosincrasia particular de una determinada cultura (TANIZAKI, 1933).

¿Cuál es la razón de que el sistema de objetos en el hábitat japonés represente un caso clave de reinvención del artefacto doméstico, a la vez fuertemente arraigado a valores y hábitos tradicionales, pero desde necesidades y lenguaje contemporáneos? Se trata de un cúmulo de circunstancias producidas durante el periodo más drástico en el desarrollo del espacio doméstico en Japón, designado con el término inequívoco wakonyousai -literalmente, con corazón japonés / al estilo occidental- y que abarca el final del período Edo ${ }^{2}$ de la periodización histórica japonesa (1603-1868) y el principio del Meiji ${ }^{3}(1868-1912)$.

A diferencia del ejemplo Occidental, donde los cambios en el desarrollo del espacio doméstico se han producido de forma gradual, desde las necesidades propias de una sociedad cambiante, el hábitat japonés, durante la segunda mitad del siglo XIX, se enfrenta a un cambio radical impuesto desde fuera, para el cual no existe una necesidad natural $y$, por tanto, para el que no está preparado.
Resumen pág 45 | Bibliografía pág 51

Arquitecta por la Escuela Técnica Superior de Arquitectura de Madrid (2009). Máster en Proyectos Arquitectónicos Avanzados (MPAA/ETSAMI UPM), 2011. Ha participado en diferentes proyectos de investigación de la ETSAM como miembro del Grupo de Investigación Paisaje Cultural (GIPC). Actualmente es doctoranda en el Departamento de Proyectos Arquitectónicos en la Escuela de Arquitectura de la UPM -título de la tesis: El hábitat japonés; director de tesis: Prof. Pedro Feduchi Canosa-. Investigadora visitante en la Universidad de Waseda (Tokio), Laboratorio de Arquitectura del Prof. Takeshi Nakagawa con beca concedida por la Unión Europea en el marco del programa BEAM (Build on Euro-Asian Mobility). Trabajo profesional: Ha trabajado en el estudio José Manuel Sanz Arquitectos (2005-2012). Ha colaborado en el desarrollo de varios proyectos de arquitectura y diseño con diferentes profesionales. 
${ }^{1}$ Abarca el final del período Edo de la periodización histórica japonesa (1603-1868) y el principio del Meiji (1868-1912).

2 Periodo Edo: también conocido como periodo Tokugawa (1603-1868); todo lo que Occidente reconoce como "particularmente japonesa" adquiere forma durante esta época 3 Durante el periodo Meiji (1868-1912) Japón comienza su proceso de modernización, erigiéndose como potencia mundial.

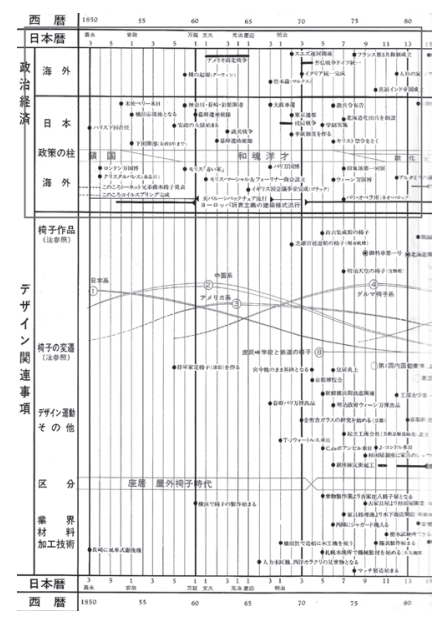

[1]

\section{Palabras clave}

Objetualidad, domesticidad, hábitat, Japón, wakonyousai, wayō setchū, silla, modernización, mobiliario

[1] Resumen de los hechos politicos y económicos acaecidos entre 1850 y 1880 dentro y fuera de Japón y que han tenido influencia directa sobre el desarrollo socioeconomico del pais e indirectamente sobre el diseño del mobiliario y la transformación del hábitat doméstico. Kagu no hakubutsukan (Museo de mueble), Tokio. 家具の年表 | その 1 | 椅子 [Kagu no hon | Sono $1 \mid$ Isu ] (Cronología de mueble | Parte 1 | La silla). 2014. Original.

[2] Traducción de la autora.

${ }^{4}$ wayō setchū : literalmente, una combinación adecuada de los mejores conceptos japoneses y occidentales.

${ }^{5_{E n}}$ Europa la primera silla documentada data del s.V aC (la silla de Zeus en el Friso del Partenón).

${ }^{6}$ Las primeras sillas documentadas en Japón son de principios del s.XII, en representaciones de monjes budistas, importadas desde China junto con la cultura del té y el Budismo.

${ }^{\mathbf{7}}$ Imagen del libro Historia ilustrada del mobiliario, basada en un bajorrelieve.

${ }^{8}$ Cabe indicar que no se trata de un ejemplo aislado; la gran mayoría de los retratos de monjes budistas a partir del siglo XII en Japón representan a la persona sentada de esta misma manera, con los pies recogidos y los zapatos posados sobre el podio.

${ }^{\mathbf{9}}$ Tomando el término "wakonyousal" desde su sentido semántico, "con corazón japonés / al estilo occidental", por supuesto, descontextualizado históricamente.

${ }^{10}$ Trabajo de investigación descrito en el libro de Tada, Karada. El cuerpo en la cultura japonesa.

\section{WAKONYOUSAI. "Modernización” del hábitat japonés en el periodo 1850-1880}

Iniciada con la reforma de estado del período Meiji, la implementación de estructuras espaciales occidentales, doctrinas políticas y sociales, así como nuevas prácticas en la vida diaria, se convierte durante la era siguiente en un arma ideológica para los deseos reformistas de crear un nuevo "moderno Japón". [1] [2]

En lo doméstico, la clave de la "modernización" reside en cambiar no simplemente un conjunto de artefactos, sino un sistema de comportamiento, cuyo discurso se designa con el término wayō setchū. Junto con la coexistencia de dos estéticas diferentes, wayō setchū ${ }^{4}$ significaba fusionar dos formas de vida -al estilo occidental, sobre sillas y pavimento duro, y al estilo japonés, sobre tatami-, hecho que conlleva una multiplicidad de prácticas espaciales y corporales, una división conceptual de los espacios y un desdoblamiento de la identidad del hábitat (TEASLEY, 2001).

Dentro del nuevo sistema de objetos que colonizan el espacio doméstico de forma repentina, la protagonista indiscutible es la silla, cuya introducción desencadena, entre otras, las siguientes consecuencias:

- cambio en el comportamiento y los hábitos corporales;

- cambio en el plano perceptivo del usuario;

- cambio del protagonismo del mueble en la configuración del espacio;

- cambio en la percepción sensitiva y afectiva del sistema de objetos.

Todos ellos obligan, en definitiva, al desarrollo de un nuevo lenguaje en la cultura material de lo doméstico, a una nueva forma de habitar, y desencadenan el inicio de un proceso de asimilación de la modernidad occidental y, a la vez, una reflexión sobre lo propio como distinto; es el inicio de la preocupación por lo característicamente japonés, desde dentro y desde fuera (ISOZAKI, 2006).

\section{Los hábitos corporales dentro del hábitat: el mueble como prolongación del cuerpo}

En todas las culturas, la arquitectura, la casa, nace desde la necesidad de envolver. Al principio, a una hoguera, alrededor de la cual el "acto de reunirse" adquiere una dimensión doméstica, por el simple hecho de estar cobijada, protegida bajo un techo. Aún así, en contacto directo con la tierra. A medida que las sociedades van desarrollándose y progresando en búsqueda de una vida cada vez más cómoda, la gran cantidad de artilugios y herramientas que surgen como prolongaciones del cuerpo, a la vez de facilitar las tareas diarias y el trabajo manual, también, en cierta medida, van alejando a la persona de su hábitat primitivo. Entre tantos, aparece el mueble que, como un corsé rígido y pesado, se ajusta a las posturas del cuerpo para hacer menos dificultosas las simples actividades del día a día: sentarse, comer, escribir, recostarse, dormir... El cuerpo se separa del suelo para sentarse en una silla, para posarse en una cama, en un acto de representación, de comodidad, de higiene.

El acto de sentarse en una silla, según la teoría de Rudofsky (TADA, 2002), se origina en la intención de imitar a un altar y, por tanto, nace como un objeto representativo para convertirse mucho más tarde en un objeto de utilidad. Las primeras imágenes que tenemos de su aparición, tanto en Occidente ${ }^{5}$ como en Japón ${ }^{6}$, son testigo de ello. A efectos de comparación en relación al comportamiento corporal, tomemos como ejemplo la representación de una silla griega ${ }^{7}$ (Occidente) y la silla del monje Enni Ben'en en su retrato datado de $1280^{8}$ (Japón). En la figura [5] vemos a una persona sentada, reposando los pies sobre un escabel. Esos mismos elementos, la silla y el escabel, están también presentes en la [4]; sin embargo, existe una diferencia fundamental en el acto de sentarse y dar uso a ambos objetos. La silla de la segunda imagen es más baja y ancha para permitir que la persona se siente con los pies cruzados en la posición loto común a las culturas asiáticas; el reposapiés cumple la función de pequeño podio para facilitar el acceso al plano de la silla y dejar los zapatos, de la misma forma en la que se dejan en el umbral al entrar en una casa japonesa. Se ha importado lo representativo, pero se ha conservado lo propio. Tal vez este sea uno de los primeros ejemplos donde cabe aplicar el término wakonyousa ${ }^{9}$ a la objetualidad en el espacio habitado. [3]

Al igual que en Occidente, donde los orígenes de la silla datan desde la antigüedad -pero no llega a convertirse en objeto de uso común hasta el siglo XVI-, en Japón, aunque por primera vez introducida a principios del s.XII con la cultura del té y el budismo desde China, la silla no se impone como mobiliario generalizado hasta la época de transición (1850-1880). Un ejemplo de este mismo comportamiento podemos observarlo en un vídeo documental realizado por Hikita Masahirō durante este mismo periodo ${ }^{10}$. Hikita instaló una cámara en el rincón de una habitación wayō setchū -amueblada con elementos japoneses y occidentales- y la dejó grabando varias horas con la intención de observar el comportamiento de la familia delante del televisor. Desde 


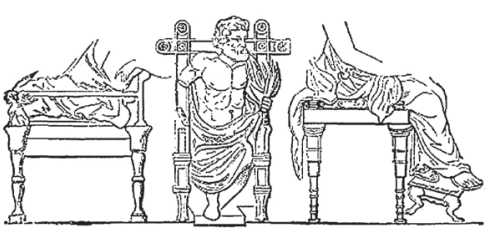

[5]

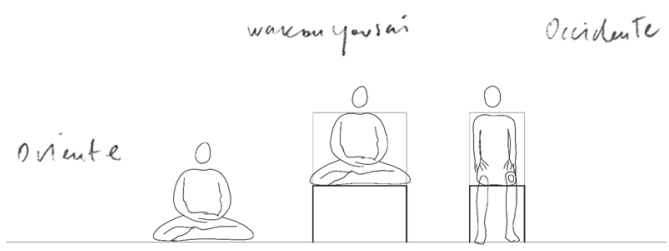

[3]

su posición inicial, sentados sobre el mobiliario occidental, algunos de los miembros de la familia empiezan a deslizarse hacia abajo para acabar sentados sobre los tatami . Una vez más, no es el mueble el que condiciona la práctica corporal, sino el hábito el que subordina al objeto desde la costumbre. El verdadero asiento es el tatami y una silla, tal vez, en este periodo transitorio, llegue a ser percibida como un tatami en un plano elevado. Una ilustración literal de ese posible concepto podría ser la silla de la figura [6], del Palacio Imperial de Tokio"1.

Mientras que los ejemplos anteriores ilustran un acto adaptativo (es decir, se importa el objeto en estado original, pero se adapta a la costumbre autóctona), la reivindicación de lo propio adquiere forma con el diseño del mobiliario a partir de la época de transición, cuando la silla se introduce de forma definitiva en la vida cotidiana. En las décadas transcurridas desde entonces se puede detectar la presencia de una corriente intencionadamente enfocada hacia la búsqueda de las raíces en el diseño contemporáneo. Algunos ejemplos podrían ser los trabajos de alumnos recopilados por Inoue Noboru en 2008 [7] [8] [9] [10]. En las descripciones de los propios autores podemos leer la voluntad de crear un objeto que "armonice con el ambiente japonés" o una silla que permita "sentarse con las piernas cruzadas"12.

\section{Plano perceptivo del espacio doméstico japonés}

La introducción de la silla también implica un cambio importante en la percepción del espacio doméstico, dado que eleva el plano de referencia del asiento y, por tanto, también la altura de los ojos. Podemos definir la perspectiva doméstica occidental como una perspectiva estable, sin apenas cambio de referencia. Muchas tareas domésticas se realizan de pie y el cambio de plano entre el acto de desplazarse y sentarse para realizar las demás se produce en un margen vertical reducido. La percepción de la casa es fija, prácticamente inalterable.

La realización de las tareas domésticas en la casa tradicional japonesa requiere un constante cambio de referencia [11]; la mayor parte de las tareas se realizan a altura del suelo, desde abrir una puerta corredera hasta preparar la comida. Desplazamos nuestro centro de gravedad desde la altura de la cadera a la altura de los pies. Por tanto, la perspectiva doméstica es variable; la casa cambia de apariencia cada vez que cambiamos de plano visual. En el contexto occidental, estas mismas tareas apenas alteran nuestro punto de gravedad desde los $80 \mathrm{~cm}-100 \mathrm{~cm}$ de la altura de la cadera hasta los $45 \mathrm{~cm}-55 \mathrm{~cm}$ de la altura de un asiento. La perspectiva desde la cual percibimos el mundo alrededor escasamente varía. [12]

Esa pérdida de referencia es otro fenómeno preocupante, acusado por la sociedad en su conjunto durante la época de transición. Entre los ejemplos más reivindicativos cuentan las películas de Ozū Yasujirō -la más representativa, Cuentos de Tokio, 1953- y la novela de Sōseki Natsume Soy un gato (1905-1906).

Las películas de Ozū ilustran la realidad de la ciudad de Tokio antes de la reforma Meiji, reconstruyendo espacios domésticos que él mismo recuerda de su niñez. Cuentos de Tokio en particular se sirve del espacio transitorio de la vivienda japonesa, denominado como wayō setchū para telón de fondo del cambio social acelerado que genera un abismo entre las generaciones. El punto de vista, como en todas las películas de Ozū, es bajo, el que corresponde a la altura de la vista de una persona sentada sobre los tatami. Esta es su forma particular de reivindicar lo auténtico, "el corazón japonés" del espacio doméstico que se ve amenazado con la llegada de la modernización. Son especialmente relevantes las escenas que retratan ambientes íntegramente amueblados de manera occidental: el punto de vista permanece inamovible, como preguntándose de qué forma puede observarse esa nueva realidad material con ojos japoneses. [13]

Esa misma reflexión late en la novela de Sōseki, quien observa los cambios sociales de forma crítica y sarcástica desde los ojos de un gato -cerca del suelo, desde donde se contemplan las cosas de forma auténtica, como se contempla y vive la casa tradicional japonesa.

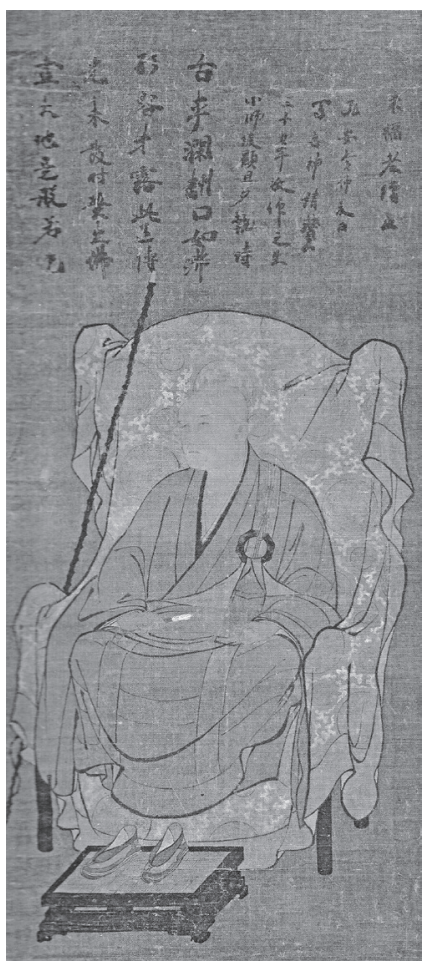

[4]

11 Silla de madera con incrustaciones de nácar del Palacio Imperial de Tokio. Imagen de archivo del Centro de Investigación del Museo Nacional de Tokio. Del libro Edo and Kyo: The Townscape in Asia, p. 78.

12 Imágenes del libro de Inoue Noboru, The Book of Chair. 2008

13 El japonés escrito hace uso de tres alfabetos distintos: los kanji, o ideogramas importados de China, en combinación con dos alfabetos silábicos propios -el hiragana, como complemento y, en ocasiones, en sustitución del anterior para el vocabulario propio, y el katakana, usado exclusivamente para palabras importadas desde otros idiomas (o para acentuar alguna palabra o frase). Ninguna palabra extranjera se escribe en hiragana.

14 Las aldeas históricas de Shirakawa-go y Gokayama fueron declaradas Patrimonio de la Humanidad dado que conservan un conjunto de casas japonesas del estilo gassho-zukuri, literalmente "construcción con las palmas de las manos unidas", nombre que reciben por la particular forma de sus tejados.

[6]

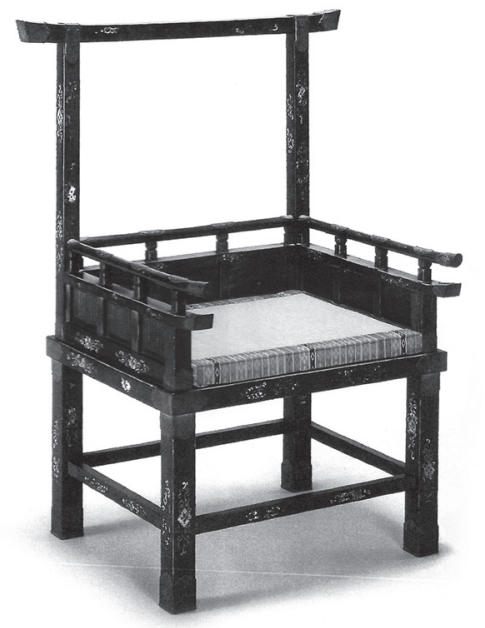




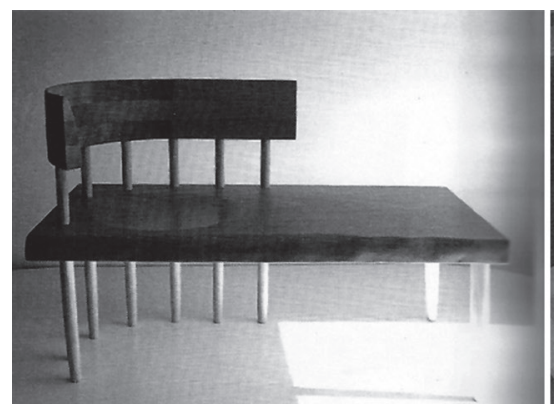

[7]

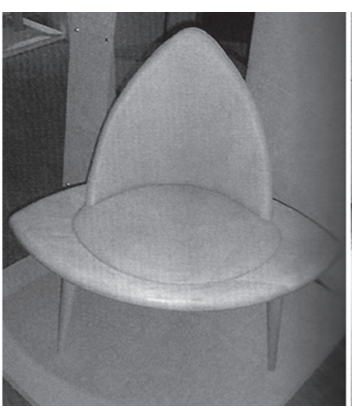

[8]

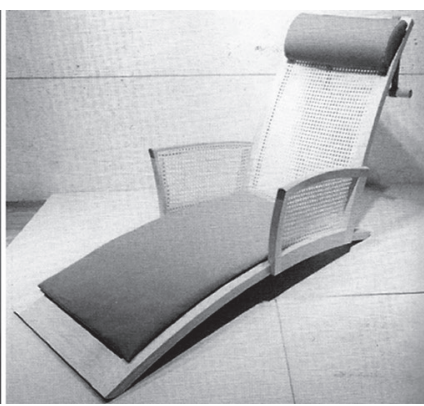

[9]

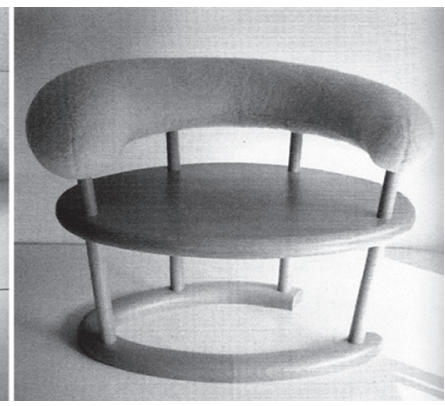

[10]
[3] El acto de sentarse y el uso de la silla en Occidente y Oriente. Boceto de la autora.

[4] Retrato del monje Enni Ben'en datado de 1280. Pintura sobre seda. Periodo Kamakura. Pieza del Templo Kofukuji, Kioto. Propiedad Cultural Importante. Ilustración del catálogo Roots of Zen: Yosai and the Treasures of Kenninji . p. 84. Catálogo de la exposición celebrada en el Museo Nacional de Tokio entre el 25-03-2014 y el 18-05-2014. Organización: Museo Nacional de Tokio, Kenninji, Yomiuri Shimbun, NHK, NHK Promotions Inc. Patrocinadores: JTB Corp., Nissha Printing Co., Ltd. Con la ayuda de: Aioi Nissay Insurance Co., Ltd.

[5] Silla griega, ilustración del libro Historia ilustrada del mobiliario, basada en un bajorrelieve p. 19. Illustrated History of Furniture. From the Earliest to the Present Time. Frederick Litchfield. 1893. En linea http://es.slideshare.net/101 ayman/illustrated-history-of-furnitureW. [Consulta de: 15.01.2015]

[6] Silla de madera con incrustaciones de nácar del Palacio Imperial de Tokio. Imagen de archivo del Centro de Investigación del Museo Nacional de Tokio. Del libro Edo and Kyo: The Townscape in Asia, p.78.

[7] Shima Shima Bench, diseño de Kiyomoto Michi. Aunque no lo dice claramente en la descripción que hace de su diseño en el libro, la silla dispone de un asiento amplio que, eventualmente, permite recoger las piernas. The Book of Chair. Noboru Inoue. 2008

[8] A Football Chair, diseño de Koshikawa, Anna. Descripción de la autora: "Al igual que demasiado redonda, ni picuda; es acogedora. Además, puedes sentarte con las piernas cruzadas o poner una taza de café." The Book of Chair. Noboru Inoue. 2008

[9] Kusu, diseño de Ono, Hiromi. Descripción de la autora: "Quería hacer una silla que acompañase a la atmósfera japonesa." La silla está concebida como un asiento a nivel de suelo que facilita el apoyo de los brazos y la espalda y ofrece una ligera curvatura para re lajar las piernas estiradas. The Book of Chair. Noboru Inoue. 2008

[10] Cloud, diseño de Abe, Makiko. Descripción de la autora: “La intención era diseñar una silla agradable para sentarse con las piernas dobladas o de cualquier otra forma, como si se estuviera envuelto en una nube y disfrutando de estar juntos." The Book of Chair. Noboru Inoue. 2008

[11] Escritorio y apoyabrazos. Cambio en el plano perspectivo del usuario. Jardín Sankei-en, Naka Ward, Yokohama, Japón. Casa Yanohara. Declarada Bien de Interés Cultural Importante. Fotografias de la autora [18-06-2012].
De todas las características fundamentales del espacio doméstico japonés, la perspectiva visual ha sido la más difícil de reconciliar con la modernización de la vivienda. En este caso la reinvención de lo tradicional ha sido sustituida por una clara delimitación de espacio occidental y espacio japonés dentro de la vivienda, del mismo modo que la escritura japonesa delimita de forma contundente las palabras propias de la importadas que se escriben en otro alfabeto ${ }^{13}$. Proyectos como la Casa ISANA de Niko Design Studio (2011), donde distinguimos un área de suelo bajo y mobiliario occidental y otra sobre plataforma elevada y cubierta de tatami, ilustran de forma clara este fenómeno. Los precedentes de dicha segregación espacial ya son visibles en ejemplos de casas construidas durante el periodo de transición, como la residencia de Asano Chuichi [14] en la aldea histórica de Shirakawa-go, declarada Patrimonio de la Humanidad en $1995^{14}$.

Con todo lo anterior, podríamos acercarnos a la afirmación de que en el contexto actual el portador del arraigo a lo japonés dentro del hábitat doméstico es el sistema de objetos que lo configura, más que la propia estancia. Se pueden detectar razones concretas que expliquen este supuesto.

\section{El protagonismo del mueble en la configuración del hábitat japonés}

Mientras en la cultura occidental el hábitat ha respondido con carácter general al concepto de contenedor en el cual los objetos domésticos se "depositan" -en la imagen de la "arquitectura como esqueleto, en el que instalar y "colgar" el mobiliario" (MORALES, 2005), en la imagen de la "casa como trastero" que "acumula" (PERROT, 2009)-, en la cultura japonesa ha sido el conjunto de objetos -en su condición de útiles domésticos, de artefactos y enseres "ambulantes"- el que ha conformado un organismo vivo, un hábitat que reúne las condiciones adecuadas para realizar las funciones básicas de la vida, un contenido habitado a lo que el contenedor ha sido subsiguiente. El espacio habitado japonés, a lo largo de su desarrollo desde la casa rural minka hasta el estilo sukiya-zukuri del siglo XVI, donde adquiere su mayor expresión formal, conserva esa misma característica primitiva de envolver sin condicionar. Abstrayéndonos del entorno y centrándonos en el comportamiento humano en el acto de reunirse, las dos escenas en la figura [15] atestiguan la misma libertad, espontaneidad y falta de coacción. Hay un espacio comprendido entre suelo y techo que fluye sin límites verticales -el techo, un conjunto de ramas y el suelo, tendido en contacto con la tierra, libre de obstáculos para tomar asiento, y sin ser condicionado por ningún artilugio adicional, como lo es la silla en Occidente.

Mientras que la silla es un objeto direccional -tiene respaldo que determina la orientación de la persona al sentarse-, dependiente -dado que posiciona las manos en un plano elevado sin

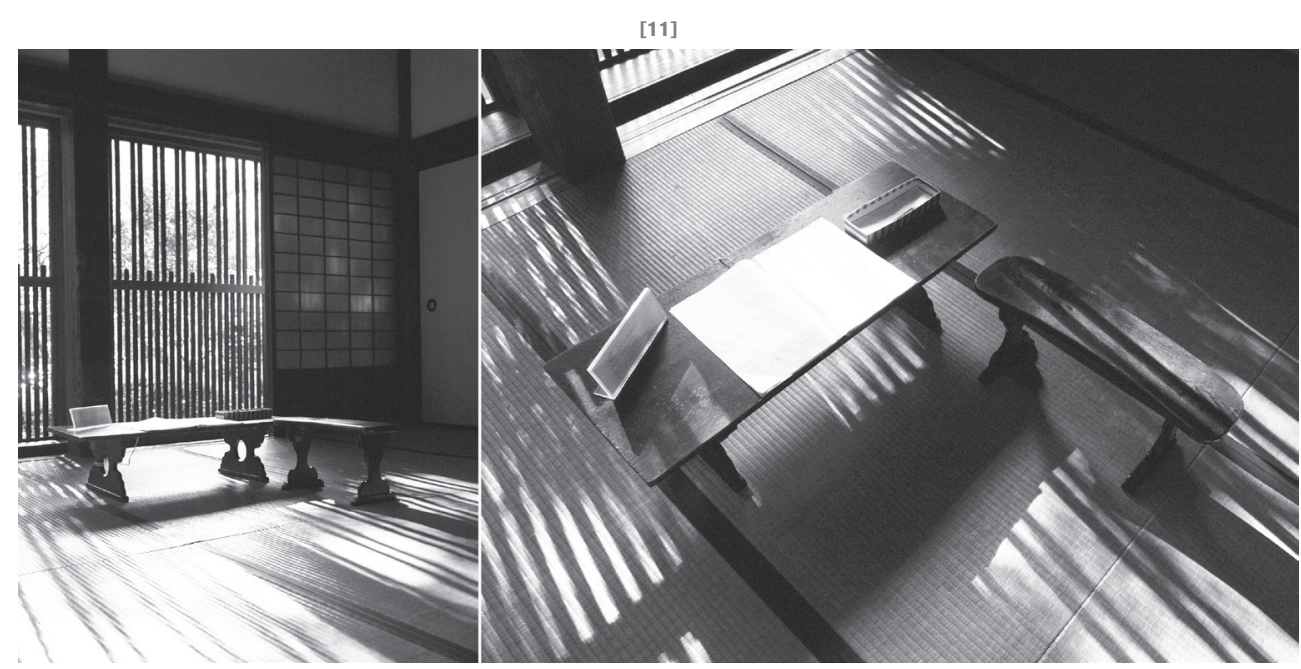




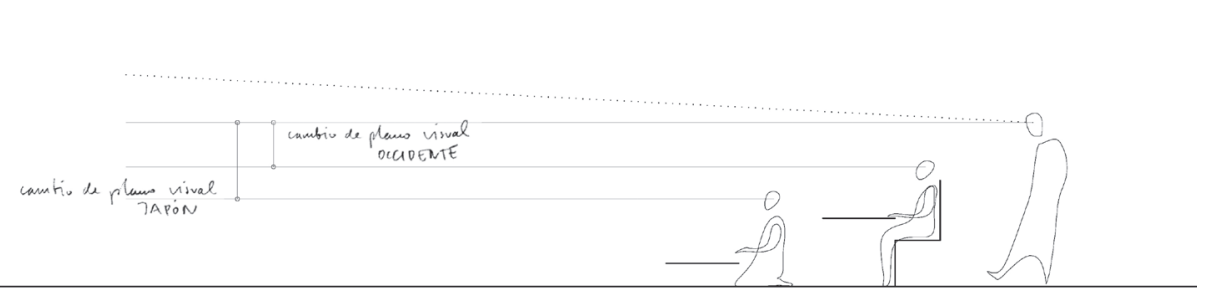

[12]

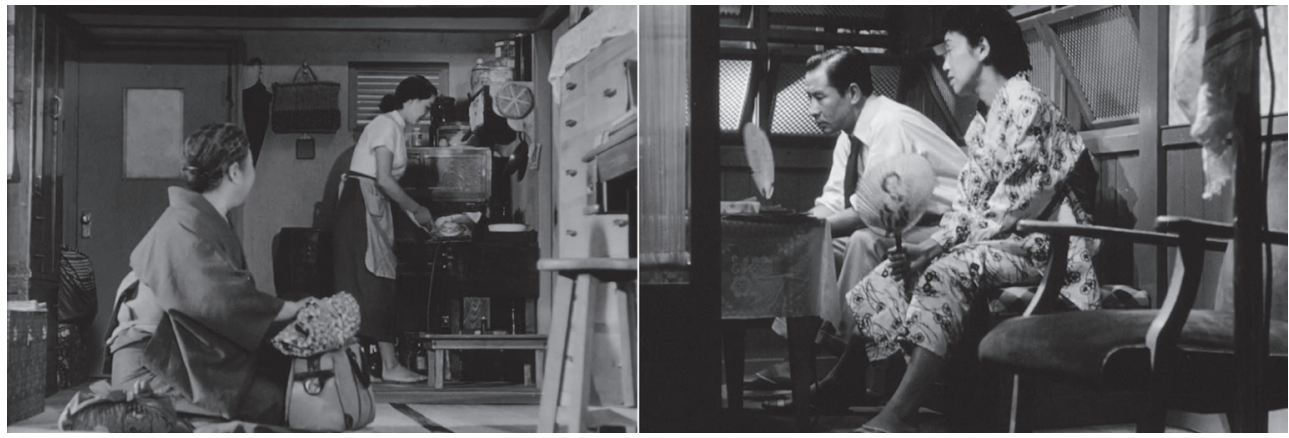

[13]

superficie de apoyo para el desarrollo de cualquier actividad-, y confiere al cuerpo un menor número de grados de libertad -obliga al cuerpo a una determinada postura-, un almohadón puesto sobre el suelo es un elemento independiente, indiferente con respecto a la orientación, y proporciona al cuerpo un punto de apoyo sin condicionarlo a la forma que debe adquirir en sentarse.

Esta configuración espacial, cuyo origen data desde el periodo Heian ${ }^{15}$, sigue latente en proyectos contemporáneos, como KAIT Workshop de Junya Ishigami (2008). Dentro de un marco flexible que permite fluctuaciones parciales de ambientes independientes dentro del conjunto global, así como reconfiguraciones instantáneas de acuerdo con las necesidades de cada momento, el sistema de objetos de nuevo cobra protagonismo como elemento configurador del espacio. El trabajo de Ishigami, tanto a nivel de proyecto arquitectónico, como en el diseño de mobiliario, podría considerarse un ejemplo claro de la forma de pensar el espacio habitado desde un lenguaje contemporáneo, pero con la presencia de una latente vocación -consciente o no- hacia ciertos valores y herencias del pasado. Lo que permite tal extrapolación es la carga simbólica que transporta cada objeto y cada espacio a través de un sistema de códigos de comportamiento y percepción de la realidad, característicos de la sociedad a la que pertenecen.
[12] Cambio del plano visual en el acto de sentarse en el espacio doméstico occidental y aponés. Boceto de la autora.

[13] izquierda: Ozū Yasujirō, Cuentos de Tokio, 1953. [Fotograma]. Escena ambientada en un entorno doméstico tradicional: los protagonistas están sentados en el suelo sobre los tatami; el encuadre deja en la esquina del primer plano la presencia de un taburete derecha: Ozū Yasujirō, Cuentos de Tokio, 1953. [Fotograma]. Escena que ilustra el uso del nuevo mobiliario occidental. El punto de vista sigue permaneciendo bajo, tal y como corresponde a la altura de la vista de una persona sentada sobre el suelo.

[14] Residencia de Asano Chuichi, Museo arquitectónico al aire libre Shirakawa-go Minka-en. Casa del estilo gassho-zukuri o "construcción con las palmas de las manos unidas". El espacio interior, pavimentado con madera, delimita pequeñas áreas de suelo elevado y cubiertas con tatami, a modo de "habitáculos" independientes dentro de un gran espacio común. De esta manera, el espacio interior empieza a separar zonas de circulación y zonas de estancia, a diferencia de la planta totalmente cubierta de esteras de tatami, que reunía las funciones de circulación, asiento, tareas domésticas y descanso sobre la misma superficie. Fotografia a la izquierda: Belén Ríos Sánchez, Investigadora visitante en la Universidad de Waseda, Tokio. Fotografía a la derecha: la autora.

[15] izquierda: Configuración espacial en una reunión al aire libre. Jardin Nacional Shinjuku Gyoen, Tokio, Japón. Hanami. Contemplación de los cerezos en flor. Boceto de la autora. [01-04-2014]. derecha: Configuración espacial alrededor del hogar abierto. Museo etnográfico de casas campesinas al aire libre Nihon Minka-en, Tama-ku, Kawasaki, Prefectura de Kanagawa, Japón Casa Sakuda. Escenificación en vivo de la vida campestre durante los siglos del XVII al XIX en Japón. Los almohadones dispersos por el suelo quedan como huellas dejadas por las personas al levantarse. Boceto de la autora a partir de fotografía expuesta en el museo. [03-05-2014]

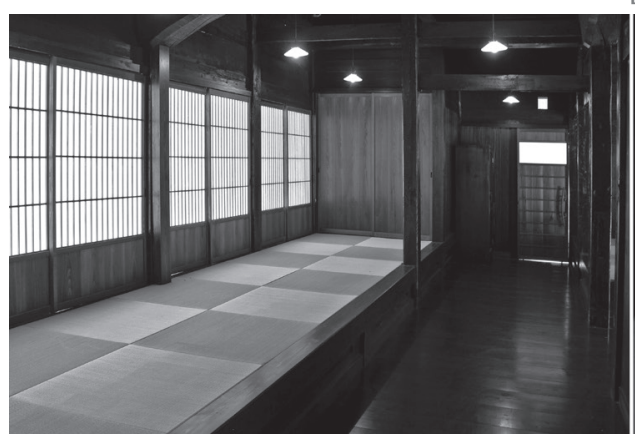

[14]

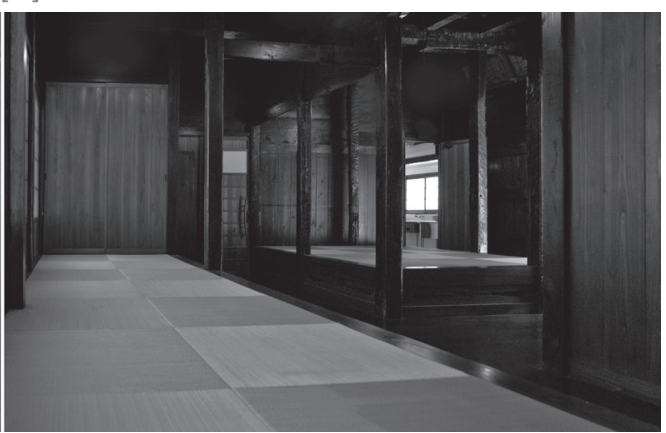

[15]

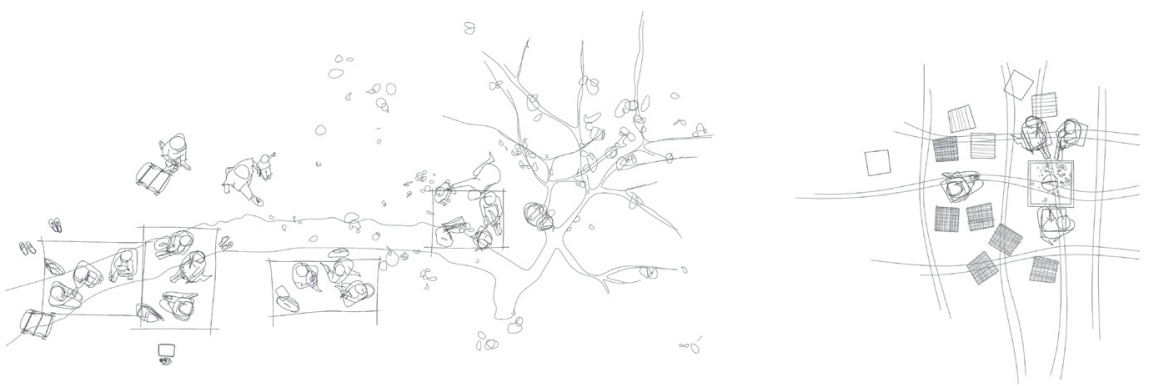




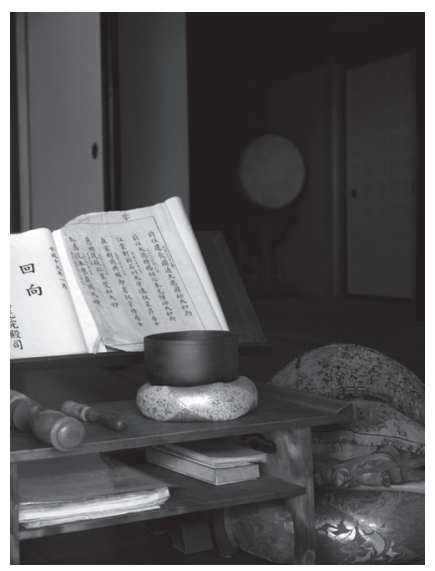

[16]

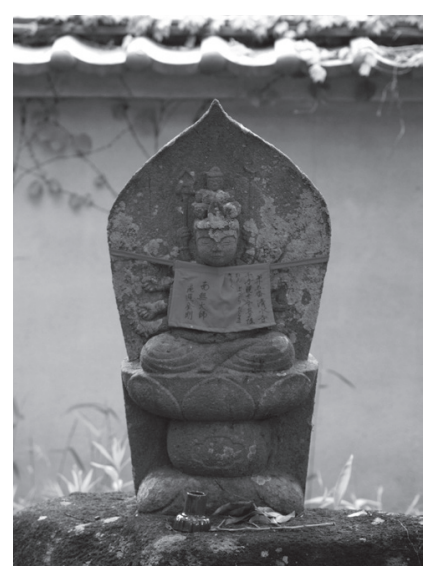

[17]

15 Periodo Heian: el último periodo de la época clásica de la historia japonesa (794-1185)

[16] Chuuzabuton. Templo Zen Jiko-in, Nara. Fotografia de la autora [29-05-2014].

[17] Yodarekake (baberos votivos). Saidaiji Temple, Nara. Fotografía de la autora [2705-2014].

[18] Elementos simbólicos en el diseño contemporáneo. Colección de sillas de Junya Ishigami, titulada Family Chairs, 2010. Dibujo de la autora.

\section{Elementos simbólicos en el diseño contemporáneo}

El hecho de que en la casa japonesa en un mismo plano se apoyan los pies, las manos y la cabeza, requiere una higiene rigurosa. Por un lado, la superficie sobre la cual se circula se mantiene en un estado de pulcritud digno de poder ser tocado con las manos y de poder reposar la cabeza. Por otro, las mismas condiciones de tacto, textura y calidez que requieren las manos se ofrecen también a los pies. Los materiales y los objetos domésticos son tratados con el cuidado que requiere la cercanía. Se suele asociar lo cercano con aquello que está "al alcance de la mano". La casa occidental, que separa rotundamente el plano de lo sucio, de los pies, del plano de lo táctil, de las manos, establece cierta categorización de lejanía con aquello que no se toca. En la japonesa, todo es táctil, todo está al alcance de la mano y esa cercanía física propicia el desarrollo de una cercanía emotiva hacia los objetos, acorde también con la forma de animismo naturalista del shinto, la religión nativa de Japón que cree que todos los objetos que nos rodean están dotados de alma. El trato hacia los objetos es un trato de respeto y atención hacia un "ente" animado.

Un ejemplo muy particular es el chuuzabuton, un cojín de tamaño reducido que sirve para absorber los posibles roces entre dos superficies en contacto. Se emplea en puntos como el apoyo de las patas de una mesa portátil para no dañar los tatami; el punto de apeo de elementos pesados -por ejemplo, un marco con inscripciones colgado encima de las entradas de los templos-; o, como en el ejemplo de la fotografía [16], el apoyo de un cuenco sobre la superficie de madera de una mesa. A diferencia de posibles equivalentes en la cultura de objetualidad occidental -donde dichos elementos de protección o se limitan a la función de proteger, dejando de lado el valor estético, o son tratados como piezas estéticas en sí mismas que, eventualmente, pueden servir como elemento de separación y protección entre dos superficies rígidas-, el chuuzabuton es una pieza pensada exclusivamente para un punto particular que, aparte de ser útil, adquiere un valor estético en sí misma. Lo útil, lo simbólico y lo estético aportan valor al objeto a partes iguales.

Mientras que el chuuzabuton es un ejemplo más abstracto, y su relación con lo sagrado no resulta a primera vista evidente, los yodarekake -o baberos votivos- [17] con los que se adornan las estatuas de las deidades para protegerlas de enfermedades a cambio de algún favor, son una muestra concreta de la práctica del animismo.

Esa sensibilidad particular hacia la entidad de los objetos sigue arraigada en la cultura japonesa del siglo XXI y, aunque probablemente de forma no intencionada, sigue revelándose en diseños tan contemporáneos como podría ser la colección de sillas de Ishigami, titulada Family Chairs del 2010. Las sillas de Ishigami son un claro ejemplo de la reinvención del objeto desde la vuelta a la tradición, convirtiéndose en "objetos ambulantes" que colonizan el espacio voluntariamente -disposición que procede de la forma de habitar la casa tradicional japonesa-. Por otra parte, en el hecho de "vestirlas" y de "calzar" los "pies" con calcetines tejidos, puede encontrarse la metáfora a los yodarekake y los chuuzabuton [18]. Por último, es difícil obviar la intención de personificar el objeto como un ente animado, procedente del sintoísmo.

Los procesos históricos son lentos y el cambio en el comportamiento de una sociedad es el que naturalmente determina la forma de la arquitectura y el espacio que nos rodea. Todo intento de impulsar un cambio en el sentido contrario resulta antinatural y despierta una reacción lícita de vuelta intencionada a lo conocido. En el caso de Japón, a este hecho se suma la particular sensibilidad de arraigo hacia lo propio, la cual, a su vez, conlleva a la especialmente aguda capacidad de procesar todo lo venido de fuera de forma que adquiera un carácter particularmente japonés. Mientras este fenómeno se ha ido nutriendo a lo largo de una escala cronológica extensa, debido a la situación de Japón de haber sido un país aislado con contadas y puntuales aperturas al resto del mundo, es durante el periodo de reforma Meiji cuando se agudiza de forma determinante.

Esta es la razón por la cual también el hábitat defiende en mayor o menor medida lo que reconoce como propio y donde la persona se reconoce como habitante de una casa y, a la vez, como japonesa. Ante la imposibilidad de reconciliar del todo el nuevo estilo de vida con cada una de las características esenciales del espacio domestico japonés, es el sistema de objetos en el ámbito doméstico el que todavía conserva aquel conjunto de características comunes que aparecen en todos los objetos diseñados por un grupo, entendiendo por grupo el conjunto de diseño japonés (NAKATANI, 2011). El sistema de objetos del espacio habitado tal vez sea el último portador de un conjunto de patrones culturales profundamente arraigados en la cultura japonesa, pero con una gran capacidad de renovarse y reinventarse, cambiando de forma para adaptarse a las nuevas circunstancias. 